\title{
Perceptions of ImmerseMe Virtual Reality Platform to Improve English Communicative Skills in Higher Education
}

\author{
https://doi.org/10.3991/ijim.v14i07.12181 \\ Juan Habib Bendeck Soto ${ }^{(凶)}$, Diana Carolina Toro Ocampo \\ Lued del Carmen Beltrán Colón, Alejandro Valencia Oropesa \\ Corporación Universitaria Remington, Medellín, Colombia \\ Juan.bendeck@uniremington.edu.co
}

\begin{abstract}
The main objective of this project was to evaluate the impact of the application of the virtual reality platform ImmerseMe as an empowering and innovative tool for learning English in a private university, as well as evaluating its possible future implementation in a private university in Medellín. It was applied in speaking activities to measure and evaluate the level of speaking of students from levels 1 to 3 , as a pilot test for the use of immersive virtual reality within the thematic units designed from the department of Foreign Languages and Cultures. The findings of the study showed that an immersive VR platform like this one is ideal to enhance the different skills of English as a foreign language (EFL) from an immersive focus considering different contexts and thinking of the development of communicative skills and interaction with native speakers in higher education. The recommendations given are for teachers and students' participation and motivation for its implementation, given the multiple advantages of immersing students in an EFL virtual environment.
\end{abstract}

Keywords-EFL, English, educational innovation, Immersion, learning, Virtual Reality

\section{Introduction}

The use of advanced audiovisual technologies for learning English as a Foreign Language has been causing a big revolution in the academic environment, becoming more common practice in Colombian institutions as a way to improve teaching and learning process in English [40], more specifically oriented to students who want to live the experience of interacting in a foreign language with the inclusion of technology.

As stated by [27], the implementation of technological applications has not been easy for language teachers, accepting that there is a struggle to introduce activities or other ICT tools that could be adjusted to current curricula, and most important, students' needs and likes.

Now, recently two concepts have been irrupting in the world of learning languages: virtual reality and immersive environments. These are correlated concepts which have their proper transversal learning approaches to generate the adoption of new languages, 
involving disciplines through the social interaction between human and computer, and the user experience with virtual objects. And it is no mystery that our students today are all "native speakers" of the digital language of computers and use of the Internet for educational focus [6], fact which can bring these new concepts to be applied altogether integrated to be taught in the classroom, with the bonus of giving students an interactive and more comfortable environment to learn a second language in a very natural, realistic environment, enabling them to communicate more effectively in the new language [28].

The actuality with the inclusion of VR in Colombian institutions, is reflected in the non-acquisition of reachable or available technology for improving the education of future professionals in a second language, not having the timely chances to use these tools in their work area [13], matter not being considered to increase student engagement with regular or complex contents but also to promote a constructivist learning, increase innovative learning experiences in any educational level, and provide scenarios where students not only visualize abstract concepts [11], but also live the experience in real-life situations.

This case study aims to explain and show the application and integration of immersive virtual scenarios through the web platform ImmerseMe applied in higher education by 4 EFL teachers to obtain more insights about the application of immersive VR in the classroom, presenting different perceptions of this tool for developing EFL skills and the ways students interact with VR in a private university in Medellín.

\section{Theoretical Background}

The conceptual framework is given from literature review of current local and international VR applications and its uses, along with the background of immersive virtual environments and information about the platform ImmerseMe and its different approaches for the development of skills in EFL. This section presents key concepts that supported the VR experience done by the EFL teachers and these are: Virtual Reality, Immersive Virtual Environments, Immersive Virtual Reality Platforms for learning a second language, and speaking and pronunciation skills in English.

\subsection{Virtual reality}

Technologies (ICTs) for learning a new language, this topic has become more familiar for many institutions and academic personnel and besides, we find that there are many institutions that take this step for an implementation that could have an impact in the different curricula of several knowledge areas, considering that new technologies are emerging and are changing at a quick pace.

Most of the papers written about VR refer to the area of education, in which describe specific applications implemented with a specific educational or training objective, and they are classified in two main groups: the ones aiming at adult training and the ones related to high school and university education [18]. 
Virtual reality is a new modality implemented within the educational sector with the purpose of generating innovative learning spaces and at the same time allowing the use of new technologies to give a new revolution to the current teaching model. VR, as its name suggests, has the user placed in front of a computer monitor interacting through a device that could be a computer or VR glasses. In immersive systems, the users' field of view is limited to the visualization display due to the use of a helmet or headset placed on the head.

The objective of the Virtual Reality is to create an experience that makes the user feel immersed in a virtual world, apparently real [13] and also provides an opportunity to leverage culturally relevant physical interaction [1]. As with any other technological advancement, the introduction of this technology causes great expectations within the academic sectors regarding the capabilities that this can offer and also to annotate that this technology is just an ICT tool that doesn't teach by itself and it has to be implemented effectively to help in the learning process [7].

As stated by [39] in their research, immersive and interactive technologies such as Virtual Reality (VR), are a new discovery which describes how we interact with fictional environments, and even how we live new experiences in reality. They also describe that VR and other immersive ICTs have a big influence in the recent transformation of the world and the way we interact with it, including the capability the concept brings to generate changes in social reality itself and the analysis to define its potential influence on how these new technologies can open up to new ways of communicating and cultural approaches.

Because the technologies of virtual reality are evolving, the applications of VR are appearing more, including the development of applications for different purposes is becoming bigger in the market. It is assumed that VR is reshaping the connection between people and information technology offering new forms of communication [2] through the concepts of immersion and interaction, trying to counteract the obstacles described and to combine, in some way, the students and the industry within the classroom.

According to [9], virtual reality integrates three concepts:

- Immersion

- Interaction

- Imagination.

1. Immersion, where the user experiences participating in the action that takes place on the screen

2. Interaction, because the virtual world responds to the user's actions in real time and it can identify and recognize the entries done by the user and react to them modifying the virtual world interactively

3. Imagination, because the system provides a user-oriented interface where it is able to solve any problem or live a different experience.

[3] also describes that the usage of VR improves performance on learning processes, simplifies the usability and improves the interaction, live different learning experiences beyond reality, involves and provides multiple perspectives in the sensorial interaction, navigates through virtual worlds that look realistic. 
[19] expresses that there are a series of characteristics or identifying qualities from VR that are common to anybody, such as the: a) Shared space; b) the user's interface; c) Real time; d) Interactive experience; e) Association with real world; and f) Socialization and creation of communities.

\subsection{Virtual reality in education}

Considering that VR can be seen as a new way to learn through immersive and interactive experiences, it can have its strengths, challenges and drawbacks applied in education, which might rely in different key factors (investment, set of applications, reception from students, motivation) that might provoke its approval or rejection. Here it is presented some general aspects to consider as benefitable features, relevant challenges and considerable drawbacks.

A research performed by [41], stated that using VR allows students to envision places, objects or even concepts they have never had access to, and besides, retain new knowledge through active knowledge development and the strengthening of critical thinking skills just by changing the environment, due to the easiness and innovative component VR provides.

A research was conducted by [42] in order to find out the favorable effects of EFL learning using VR devices and avatars on elementary school students. This study divided students in three segments: a group using Kinect, a group using the VR platform Second Life, and a group using traditional methodologies with regular materials. The findings demonstrated that students preferred to learn EFL through VR devices instead of gaming devices or traditional methodology; this was because of the outstanding results obtained using VR, while using physical resources didn't show any improvement.

Nevertheless, using VR in a classroom could have some drawbacks and challenges to face. As stated in [5] and [46], here are some drawbacks and challenges that could come up from the use of VR in educational and cultural contexts:

\section{Drawbacks:}

- VR might require the ideal headset and VR devices, in order to provide the desired immersion and interaction, along with an accurate implementation.

- VR could be hindered in the implementation due to teachers' and students' generational gap. Teachers or students from a previous generation reject these technologies and new ways of teaching or learning.

- VR requires the adjustment of curricula that could be compatible with different knowledge areas, and include the different educational outcomes that will derive from its implementation.

\section{Challenges:}

- The cost for a good headset is highly expensive and difficultly affordable for most of the institutions; as these technologies are evolving, their price goes high just as their applications.

- Demonstrations in different knowledge areas must be performed, so people (teachers and students) can know all about these technologies. 
- Premium accounts are required in order to obtain the full experience, and the challenge here is the affordance of institutions to buy the necessary licenses to use them in the classroom.

\subsection{Immersive virtual environments}

According to [12], virtual reality applications introduce an aftermath known as "immersion", where students can interact with a virtual environment using the human senses and the use of special devices are connected to a computer.

As stated in Ref. [10], an immersive virtual environment (IVE) is defined as a space where the user is inside and can increase the sense of presence being within it, and which consists of synthetic sensory information that provides a surrounding and continuous stream of stimuli, creating the illusory perception of being enclosed within and interacting with a real environment [36], [35].

Based on the work of [38] and [22], virtual reality is classified by the levels of interaction and immersion that provide the user:

- Non-immersive VR systems: It is simply made up of a desktop computer with common features, with the ability to display simulations that are explored through the use of peripheral devices. These systems completely lack immersion sensations for the user.

- Virtual immersive VR system: Provide users the sensation of being slightly immersed in a virtual environment, commonly executed through specific categories of software.

- VR system of total immersion: These systems are composed of a pair of threedimensional visualization screens where a helmet is worn on the user's head, which allow to be completely disconnected from the physical world. In immersive environments, it is necessary to use special hardware to be able to interact with the environment.

\subsection{Immersive virtual reality platforms for learning a second language}

There have been many projects related to the use of immersive VR platforms where a literature review is shown by [18], expressing the general concepts for the use of VR and its different applications whether if it is through special VR devices or by the use of specific desktop or VR applications.

A project called MACH (My Automated Conversation Coach) was presented by [33], as a technology which used virtual automated elements (virtual objects) with a conversational component to allow people to improve conversational skills in EFL, contemplating different aspects in the evaluation of the speaking such as the expressiveness, the listening behavior, the acknowledgement from the virtual objects and the duration of the activity. The results obtained from its application were successful, and people who interacted with the platform agreed with the use for practicing 
conversational English, due to the fact that they felt comfortable and confident talking to the virtual object expressing their ideas and receiving feedback for their performance.

Consequent studies with the use of emerging technologies (VR or Augmented Reality), alternated the focus of this application to the use of instruction involving computer simulations with traditional instructional methods. [44] performed 32 related studies and discovered that the use of these simulations contributed to the development of higher cognitive results and better attitudes from learners towards learning, compared to the results of teaching methods, and also promoted self-directed learning and failsafe learning environments. Thus, applying these technologies make teachers design meaningful learning environments, from the part of increasing the order of difficulty to communicate, using all these elements in the classroom [45].

Applications like MondlyVR, ImmerseMe or LearnEnglishVR are applications that allow a student to learn a language through virtual reality in a much simpler and easier way and in turn, boost the basic skills required to speak a second language such as are: listening, speaking, reading and vocabulary.

ImmerseMe: ImmerseMe is a platform adjustable for language teachers which offers a practical and personalized focus on real-life scenarios improving speaking and pronunciation skills through pronunciation instruction, allowing students not only learn different sounds, but also improve their speaking skill [30] through the interaction with virtual objects.

This platform came up as an idea by Scott Cardwell in 2015 as an initiative to promote a non-immersive or immersive virtual reality platform with a gamification component, which allows the student to interact with a person in a simulated real-life environment where, while completing the different sessions, it obtains points for each completed activity depending on the difficulty of the scenario (beginner, intermediate, advanced).

The platform offers scenarios such as buying a coffee in a cafeteria, buying drinks in a store, discuss real life issues in different knowledge areas, using situation awareness where humans can naturally interact with the platform through spoken language without being conscious or to follow any type of rule that can't let him/her express freely [17].

\subsection{Speaking and pronunciation skills in English as a foreign language}

When we talk about speaking and pronunciation skills, as stated in [31], teachers have to consider that there is a mix of students with different abilities in a classroom, expectations, motivation, knowledge and every one of them manages different learning paces. Within the speaking skills, teachers must consider that it requires the advancement of different aspects of the language, and requires patience and guidance to let them express their ideas and engage in communication effort [32] in order to promote a demonstrative environment in the classroom that could give them comfort and confidence.

As stated in Ref. [30], it is accentuated that communication is an important concept to explain because this means that students through practice (whether if it is with a native speaker or with the teacher him/herself), even though they could make mistakes, they can make themselves be understood to teachers and peers with some pronunciation 
details to correct (this is the teacher's responsibility to assure that errors can be the least possible).

Research Questions:

After reviewing all the theoretical background related to the case study, 2 research questions were proposed in order to carry out the application of the platform ImmerseMe:

1. In which way the ImmerseMe platform could contribute to the boost of communicative skills of students in higher education?

2. How can VR immersive platforms improve the English language learning through the interaction with virtual native speakers?

\section{Method}

The method used for this research is of a qualitative nature with an exploratory and descriptive approach using a quantitative component, given that it examines a topic or research problem that has been studied in different positions, and of which there are many inquiries or has not been addressed previously [16]. It is important for qualitative researchers to employ several methods for collecting empirical data that together or separately provide significant insights [49].

\subsection{Data gathering}

To collect the evidence of their opinion about the platform firstly, a semi-structured survey was created online (www.surveymonkey.com), which included open and closed questions, and questions based on a Likert scale (or Likert type), which had the purpose of understanding the perceptions of the participants related to a single phenomenon of interest [15], considering the interaction and the usability of the platform. Later, they were asked about if the platform could be useful to improve other EFL skills in their respective levels, and if there had to be any previous knowledge before using the platform.

Secondly, it was developed a document analysis, where the syllabus from the different levels were taken to be analyzed and determine which topics were going to be selected for the application. The documental analysis was chosen as the second method to apply because it works as a collaborative data gathering with qualitative interviews and endows a study among this process [47]. The syllabus of the area provided a fair background previous to the design of the interviews, due to the fact that this allowed researchers to define the evidence obtained and the details to highlight from the different responses of the interviews, and also get the observational data from all the experience [48].

Finally, it was applied a participant observation where the center of the study was the students' activity during the use of the ImmerseMe platform. The observation was focused on a formative level and it is the only method used in every qualitative research [16] to be able to see students' performance in any regular or innovational activity. 


\subsection{Participants}

Within the activity, 124 students of different semesters of levels 1 to 3 were selected as a heterogeneous systematic random sample to perform a Speaking test with the ImmerseMe platform, as an evaluation instrument for a test corresponding to the regular activities scheduled and evaluated within the semester through the use of ImmerseMe. These students had a variable English level (Basic, Intermediate) and belonged to different semesters from different faculties, where they regularly interact throughout the entire semester.

\subsection{Procedure}

Before the use of the platform, they were asked about previous experience with VR or terminology related to the term outside the classroom, in order to know more about their knowledge about current emerging technologies. Additionally, a vocabulary about VR was given by each teacher, in order to students understand the purpose of the case study (words like immersive, Virtual Reality, Interaction and virtual objects).

After the warm-up and the introduction, a random student was selected to perform a simulation test on the ImmerseMe platform in order to calibrate the required devices (headset, requirements of the platform in the used computer, audio devices); then, student by student was accessing the platform with a specific speaking activity assigned by the teacher, considering the context of their professional careers. The mechanics of the use was based on speaking and pronouncing the conversation properly with a virtual native speaker of the platform. Then, unless the student speaks and pronounces properly, the platform wouldn't let him/her advance to the next part of the conversation. After the evaluation, students were required to take the semi-structured survey.

\section{$4 \quad$ Results and Discussion}

Within the results obtained from the survey applied to students, we could realize that the impact of the platform in the classroom was high and it was well received by the students, along with the obtained results. In addition, it could be seen that these students are very eager and demanding with the implementation of new modalities of teaching and learning, specially learning English as a Foreign Language (EFL) in an innovative way.

Moreover, within the use of the platform, some negative points were observed through the results, mainly by students whose work was not proper. This is because most of them are very accustomed to a traditional teaching style, which plays a key factor to adapt in newer teaching methodologies, and which could not be useful with students from this generation. This premise is marked based on the acknowledgement that students are not equal and each student handles a very different learning pace.

The following items were considered within the survey as the most relevant to show and discuss: Previous Knowledge Management, Impact of immersive virtual reality and the development of skills through immersive virtual reality. 


\subsection{Management of prior knowledge}

In this question, it was observed that the great majority, due to their low English level, considered that they must have previous knowledge to be able to use this platform.

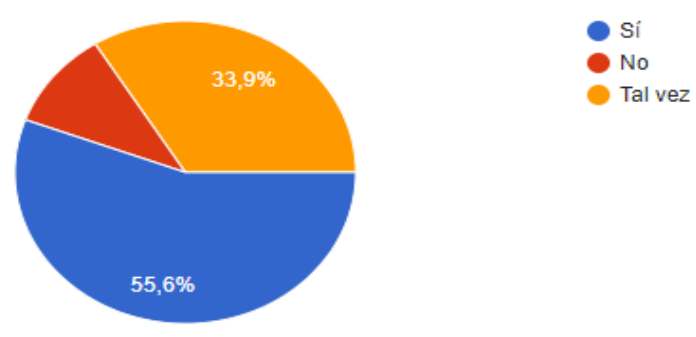

Fig. 1. Question 1: Do you consider that, for interacting with this platform, should you have previous knowledge?

Consequent to this, it was observed that a significative percentage detected within each of the groups had previous knowledge and was proved in the results obtained during the tests conducted in the platform, since their comments were positive about the platform. Therefore, seeing that even students with little knowledge performed this test and were successful, the ImmerseMe platform assures that, as stated in [4], learners interact with the environment and learning objects in real-time at the same time.

It was also found that the vast majority of students had an acceptable level of confidence to perform a different activity for the evaluation of a competence such as speaking, and it was also observed that the students felt very comfortable doing this activity in small groups and not doing it in front of all the group of students, despite of their fears or limited motivation in the subject.

Moreover, students must recognize that these tools contribute to the positive development of personality factors like self-esteem, assuming the risk and most of all, motivation, because developing motivation by using technology could assure a natural figure between gamification and learning a second language, which results in the enhancement of the VR experience [23].

\subsection{Impact of immersive virtual reality}

Within the results observed from the survey applied to students, we realize that the impact of the platform in the classroom was well received by the students of the private university, as stated in [8], where it expresses that when the distractions are blocked in the classroom, VR empowers students' potential to assist and connect them with the VR material, similar scenario to the one applied during the use of immersive VR, because it shows the their exigences when carrying out activities under new modalities of teaching and learning, specially to learn English as a Foreign Language. It is not 
coincidence that colleges or universities will continue using VR technology to allow students to get immersed in different worlds so they can share these experiences with other peers [5].

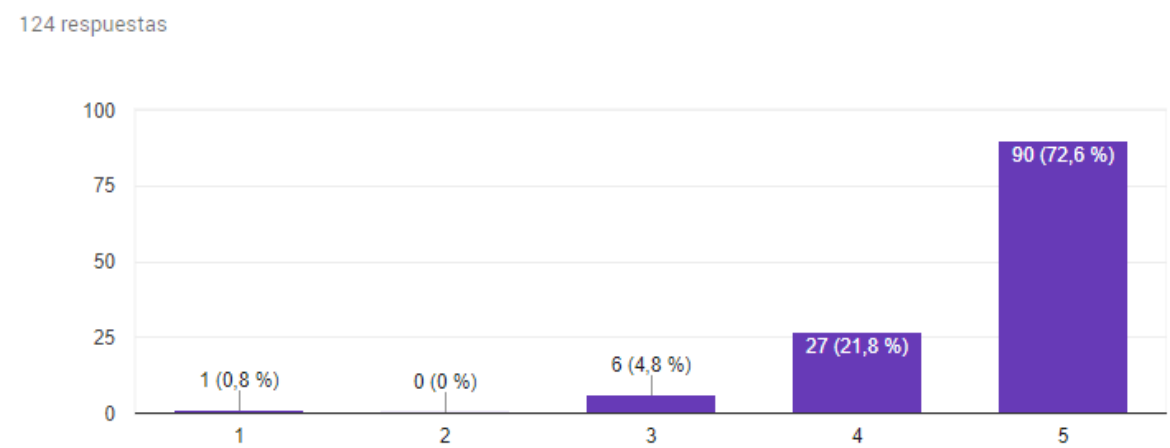

Fig. 2. Question 2: How was your experience with the ImmerseMe platform?

Besides, the negative responses in the survey were from students whose performance in the test was not the most successful and because they are students accustomed to learn through traditional teaching type. Consequently, pointing to the teacher's role, when a traditional or innovative teaching is handled throughout a course, the student automatically adapts to this type of teaching, which in many cases such models can be successful or a failure depending on the type of student in the groups. One of the advantages using Immersive VR in education, is that it overcomes physical barriers of place and time, and allows a virtual experimental space [37] for students to learn and develop skills.

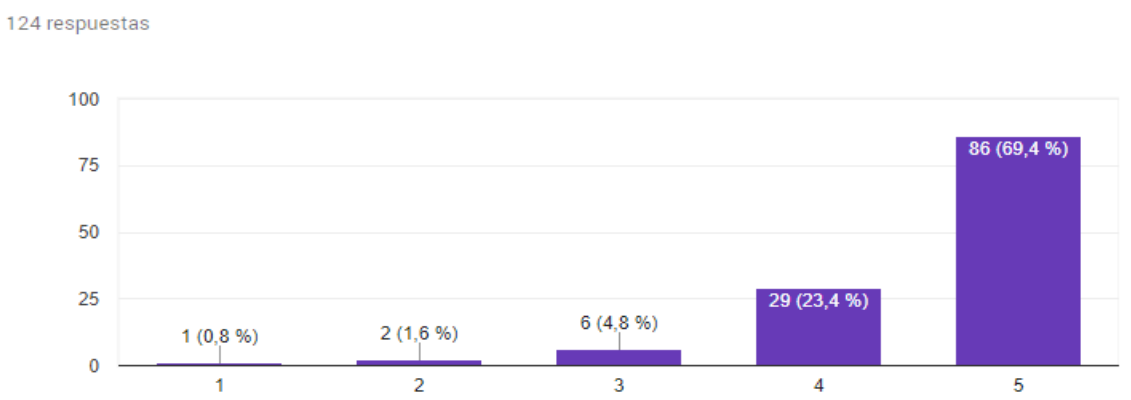

Fig. 3. Question 3: How would you evaluate the application of topics seen in class through this platform?

For students whose results were satisfactory, they were pleased with the use of the platform, and agreed that it could be implemented permanently in the university to enhance communicative abilities. This result is highlighted because it is well known that 
each student manages different learning paces, knowing that introducing the concept of immersive VR within the university generated many expectations among all students.

One of the aspects to consider is that the advantages VR offers to education are appreciable, since the fact that this platform (ImmerseMe) has immersive features, gives an added value and a beneficial bank of scenarios that can capture the student's attention [14].

\subsection{Skill development through ImmerseMe}

Extending the other questions, it was noted that, when students are immersed within this platform enhances not only speaking skill, but also reading and allows students to gain more vocabulary. As [20] mentions, to immerse a student virtually is to allow him/her to feel physically present in a non-physical authentic environment, which can allow him/her to be in a customized environment, engaged in terms of participation and most importantly, self-paced that can guarantee students' success [21] in learning and mastering different skills.
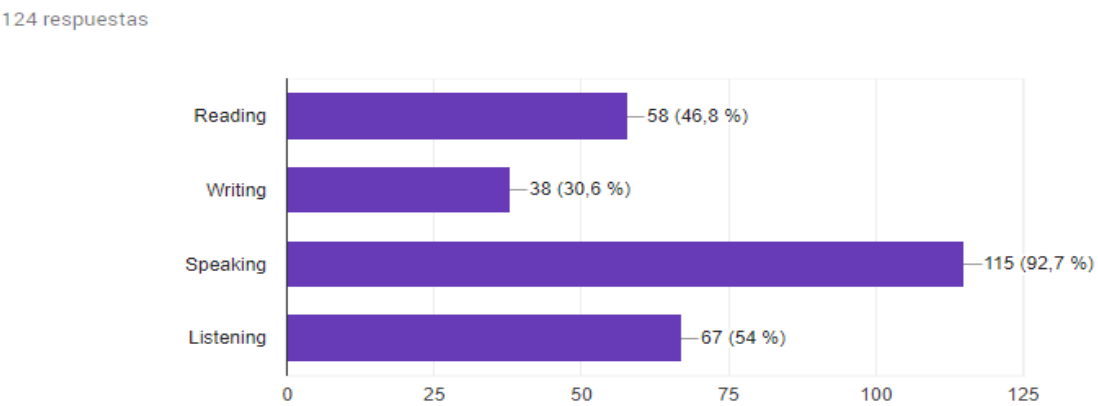

Fig. 4. Question 4: Which skills do you consider will improve with the use of this tool?

Based on the theory mentioned by [24] regarding learning a second language, ImmerseMe comprises its own focus on how to communicate interacting in the native language, inclusion of original texts oriented to a specific situation, improvement of the student in personal experiences and gain of new learning elements, and the connection between classroom language learning and activities outside the classroom.

For those students whose results were satisfactory, they agreed with the implementation of ImmerseMe in the university, so all can enhance the communicative ability through the speaking and reading, especially because of the interaction with a native speaker. This was identified as positive, because when a student meets a native speaker, it gives more security and the opportunity of knowing different accents and expressions, because the more a student practices, the better the interaction with native speakers will be [26]. 


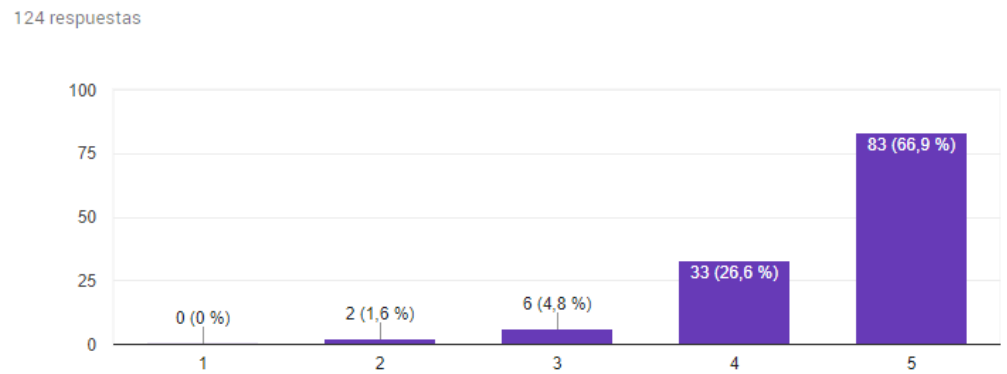

Fig. 5. Question 5: In a 1(Deficient) to 5 (Excellent) scale, how would you evaluate the interaction with a native speaker in a real-life scenario through the platform?

According to the statements in [25], it has to be considered the type of speech and the scenario students will be involved during the immersive experience, since they must acknowledge that when they are in a real-life scenario, many words or sentences can come out, as fluency, clarity and ideas organization can lead to an effective communication. Therefore, this can be a significant factor when speaking of human interaction in real life or a virtual world, because it is important to use VR for training purposes, considering the practice of specific skills to be used in real life. This concept is given since both teachers and students have to consider that skill transfer or development is important, but human behavior and performance must be reflected in the virtual environment as well [34].

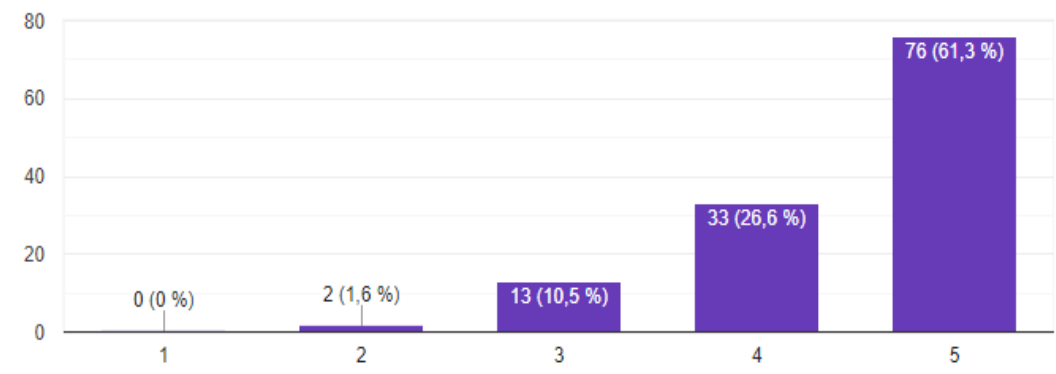

Fig. 6. Question 6: On a 1 (Nothing) to 5 (All the time) scale, how often would you recommend the use of this platform in your English class?

Based on these results, it is reflected that ImmerseMe can become an important acquisition within the institution for students to improve their English level and also to be supportive with those who have difficulties when expressing their ideas verbally in EFL. Also, from the researchers' point of view, it was relevant to see how students gain more confidence at the time of reading and speaking in English, allowing to express him/herself in a better way without fear of making mistakes and with motivation to learn. 


\section{Conclusion}

After the application of the platform, it was important to mark the following conclusions:

After the execution this study, it could be determined that the use and application of immersive virtual reality platforms as ImmerseMe, is a process in a state of maturation within our country (in this case, Medellín), which indicates that for many institutions to improve the quality of the process of teaching and learning processes, they must begin to incorporate new technologies with greater intensity in the classroom.

We can state that the benefits of VR are a good trigger for meaningful learning experiences in the classroom. Considering the overall performance of the students, this could be considered as meaningful learning because of their hard work and the increase in their progress of communicative skills within the application.

Among some premises to solve and questions to ask about VR, the current premises involve educators or students who live in this era, due to the fact that these emerging technologies must be taken as relevant, although they could show their drawbacks and challenges. All this package of factors should engage the student, add creativity and innovational components to the classroom and make interactivity a key differential factor in teaching and learning environments.

The ImmerseMe platform was received as an optimal option for learning English language because it is considered a VR communicative technology oriented to real life, where its scenarios allowed students to master English language in different contexts.

Based on the obtained results, it showed that the platform was successful and challenged them to speak, read and listen in a much more fluent and clearer way. Additionally, this VR platform is compatible with constructivism, which encourages students to explore, experiment and interact to develop new skills and concepts (vocabulary, pronunciation and listening) through the interaction with virtual objects.

\section{References}

[1] A. Cheng, L. Yang and E. Andersen, "Teaching Language and Culture with a Virtual Reality Game," in In Proceedings of the 2017 CHI Conference on Human Factors in Computing Systems, New York, 2017. https://doi.org/10.1145/3025453.3025857

[2] O. Erenay and M. Hashemipour, "Virtual Reality in Engineering Educa-tion: A CIM Case Study," The Turkish Online Journal of Educational Technology - TOJET, vol. 2, no. 2, pp. 51-56, 2003.

[3] J. Sánchez, M. Lumbreras and J. Silva, "Virtual Reality and Learning: Trends and Issues," pp. 1-4, 2001.

[4] H. Huang and S. Liaw, "An Analysis of Learners' Intentions toward Virtu-al Reality Learning Based on Constructivist and Technology Acceptance Approaches," International Review of Research in Open and Distributed Learning, vol. 19, no. 1, pp. 91-115,2018. https://doi.org/10.19173/irrodl.v19i1.2503

[5] D. Velev and P. Zlateva, "Virtual Reality Challenges in Education and Training," International Journal of Learning and Teaching, vol. 3, pp. 33-37, 2017.

[6] M. Prensky, "On the horizon," vol. 9, no. 5, p. 1, 2001. 
[7] C. Chen, "The design, development and evaluation of a virtual reality-based learning environment," Australasian Journal of Educational Technology, vol. 22, no. 1, pp. 39-63, 2006.

[8] R. Gadelha, "Revolutionizing Education: The promise of virtual reality," Childhood Education, vol. 94, no. 1, pp. 40-43, 2018. https://doi.org/10.1080/00094056.2018.1420362

[9] F. Wilches, "El nuevo paradigma educativo:" realidad virtual vs. aprendi-zaje virtual"," Revista Colombiana de Educación, no. 38-39, pp. 1-7, 1999. https://doi.org/10.17227/ 01203916.5440

[10] J. Bailenson, N. Yee, J. Blascovich, A. Beall, N. Lundblad and M. Jin, "The use of immersive virtual reality in the learning sciences: Digital transformations of teachers, students, and social context," Journal of the Learn-ing Sciences, vol. 17, pp. 102-141, 2008. https://doi.org/10.1080/10508400701793141

[11] E. Hu-Au and J. Lee, "Virtual reality in education: a tool for learning in the experience age," Int. J. Innovation in Education, vol. 4, no. 4, pp. 215-226, 2017.

[12] J. Hilera, S. Otón and J. Martínez, "Aplicación de la Realidad Virtual en la enseñanza a través de Internet," Cuadernos de documentación multime-dia, vol. 8, pp. 25-35, 1999.

[13] V. Obrist and E. Martínez, "Aplicación de la Realidad Virtual en una ex-periencia de aprendizaje," in X Congreso de Tecnología en Educacion \& Educacion en Tecnología, Ciudad del Este, 2015. https://doi.org/10.24215/18509959.21.e01

[14] A. Otero and J. Flores, "Realidad virtual: Un medio de comunicación de contenidos. Aplicación como herramienta educativa y factores de diseño e implantación en museos y espacios públicos," Icono 14, vol. 9, no. 2, pp. 185-211, 2011. https://doi.org/10.7195/ri14.v9i2.28

[15] A. Joshi, S. Kale, S. Chandel and D. Pal, "Likert Scale: Explored and Ex-plained," British Journal of Applied Science \& Technology, no. 7, pp. 396-403, 2015. https://doi.org/10. 9734/bjast/2015/14975

[16] R. Hernández, C. Fernández and L. Baptista, Metodología de la investi-gación, México, D.F.: McGraw Hill, 2014.

[17] K. Nagao and J. Rekimoto, "Ubiquitous talker: Spoken language interaction with real world objects," arXiv - Cornell University, pp. 1-11, 1995

[18] L. Freina and M. Ott, "A Literature Review on Immersive Virtual Reality in Education: State of The Art and Perspectives," in eLearning and Soft-ware for Education (eLSE), Bucharest.

[19] F. \&. G. M. Gértrudix, "Music in Virtual Worlds. Study on the Representation Spaces.," Revista Comunicar, no. 38, pp. 175-181, 2012. https://doi.org/10.3916/c38-2012-03-09

[20] M. \&. P. Y. Oliva, "Internet resources and second language acquisition: An evaluation of virtual immersion," Foreign Language Annals, vol. 28, no. 4, pp. 551-563, 1995. https://doi.org/10.1111/j.1944-9720.1995.tb00828.x

[21] M. Smith, E. Ginger, K. Wright, M. Wright, J. Taylor, L. Humm and M. Fleming, "Virtual reality job interview training in adults with autism spectrum disorder," Journal of Autism and Developmental Disorders, vol. 44, no. 10, p. 2450-2463, 2014. https://doi.org/10.10 07/s10803-014-2113-y

[22] E. Ai-Lim and K. Wai, "A Review of Using Virtual Reality for Learning," En Transactions on edutainment I, vol. 5080, pp. 231-241, 2008.

[23] J. Figueroa Flores, "Using Gamification to Enhance Second Language Learning," Digital Education Review, vol. 37, no. 27, pp. 32-54, 2015.

[24] S. Malone, "Theories and Research of Second Language Acquisition," 2012. [Online]. Available: http://www.sil.org/sites/default/files/files/theories_and_research_of_second language_acquisition.pdf.

[25] J. Richards, Approaches and Methods in Language Teaching. Second edi-tion, Cambridge University Press, 2001. 
[26] M. Kreisa, "5 Ways Anyone Can Learn Languages with Virtual Reality," June 2019. [Online]. Available: https://www.fluentu.com/blog/virtual-reality-language-learning/

[27] M. I. Espitia and A. Clavijo Olarte, "Virtual Forums: A Pedagogical Tool for Collaboration and Learning in Teacher Education," Colombian Ap-plied Linguistics Journal, vol. 13, no. 2, pp. 29-42, 2011. https://doi.org/10.14483/22487085.3763

[28] J. McDougald, "The use of new technologies among in-service Colombian ELT teachers," Colombian Applied Linguistics Journal, vol. 15, no. 2, pp. 247-264, 2013. https://doi.org/ 10.14483/udistrital.jour.calj.2013.2.a07

[29] J. Cabero Almenara and J. Barroso Osuna, "The educational possibilities of Augmented Reality," Journal of New Approaches in Educational Re-search, vol. 5, no. 1, pp. 44-50, 2016. https://doi.org/10.7821/naer.2016.1.140

[30] J. Harmer, The Practice of English Language Teaching, London: Long-man, 2001.

[31] E. Taddese, "The Practice of Teaching Speaking Skills: the case of three Secondary Schools in Gedeo Zone, Ethiopia," IOSR Journal of Humanities and Social Science, vol. 24, no. 3 , pp. 40-47, 2019.

[32] G. Brown and G. Yule, Teaching the Spoken Language, Cambridge: Cambridge University Press, 1983.

[33] M. Hoque, M. Courgeon, J. Martin, B. Mutlu and R. Picard, "In Proceedings of the 2013 ACM International Joint Conference on Pervasive and Ubiquitous Computing," in MACH: My Automated Conversation Coach, New York, 2013. https://doi.org/10.1145/2493432. 2493502

[34] R. Kalawsky, "In Proceedings of the Presence Workshop'00," in the validity of presence as a reliable human performance metric in immersive environments., The Netherlands, 2000.

[35] J. Smith, "Immersive virtual environment technology to supplement environmental perception, preference and behavior research: a review with applications," International Journal of Environment Research and Public Health, vol. 12, no. 9, p. 11486-11505, 2015. https://doi.org/10.3390/ijerph120911486

[36] J. Loomis, J. Blascovich and A. Beall, "Immersive virtual environment technology as a basic research tool in psychology.," NCBI, vol. 31, no. 4, pp. 557-564, 1999. https://doi. org/10.3758/bf03200735

[37] K. Hew and W. Cheung, "Use of three-dimensional (3-D) immersive virtu-al worlds in K12 and higher education settings: A review of the research," British Journal of Educational Technology, vol. 41, no. 1, pp. 33-55, 2010. https://doi.org/10.1111/j.1467-8535.2008. 00900.x

[38] D. Fällman, A. Backman and K. Holmlund, "Universitets Pedagogisk Konferens," in VR in Education: An Introduction to Multisensory Con-structivist Learning Environments, 1999.

[39] J. Rubio-Tamayo, M. Gértrudix and F. García García, "Immersive Envi-ronments and Virtual Reality: Systematic Review and Advances in Communication, Interaction and Simulation," Multimodal Technologies and Interaction, vol. 1, no. 21, pp. 1-20, 2017. https://doi. org/10.3390/mti1040021

[40] J. McDougald, "The State of Language and Content Instruction in Co-lombia," Latin American Journal of Content \& Language Integrated Learning, vol. 2, no. 2, pp. 44-48, 2009. https://doi.org/10.5294/laclil.2009.2.2.15

[41] G. Javidi, "Virtual Reality and Education," [Online]. Available: https://pdfs.semanticscholar.org/7ae1/08ef0dea4a4b8f705fa22cf4aef7f0108d9d.pdf.

[42] Y.-J. Lan, W.-C. Fang, I. Y. T. Hsiao and N.-S. Chen, "Real body versus 3D avatar: the effects of different embodied learning types on EFL listen-ing comprehension," Educational Technology Research and Develop-ment, vol. 66, no. 3, pp. 709-731. https://doi.org/10. $\underline{1007 / \mathrm{s} 11423-018-9569-\mathrm{y}}$ 
[43] M. Reyzábal, "El aprendizaje del español como segunda lengua en un marco intercultural.," in Diversidad étnica y cultural en las aulas, Madrid, La Muralla, 2003, pp. 137-155. https://doi.org/10.14201/gredos.124199

[44] J. J. Vogel, D. S. Vogel, J. Cannon-Bowers, C. A. Bowers, K. Muse and M. Wright, "Computer gaming and interactive simulation for learning: A Me-ta-analysis," Journal of Educational Computing Research, vol. 34, no. 3, pp. 229-243, 2006. https://doi.org/10.2190/flhvk4wa-wpvq-h0ym

[45] N. Moreno, J. Leiva, M. Galván, E. López and F. García, "Realidad au-mentada y realidad virtual para la enseñanza aprendizaje del inglés desde un enfoque comunicativo e intercultural," in Innovación docente y uso de las TIC en educación, Málaga, UMA Editorial, 2017. https://doi.org/10.5377/ryr.v41i0.2757

[46] M. Vafadar, "Virtual Reality: Opportunities and Challenges," International Journal of Modern Engineering Research (IJMER), vol. 3, no. 2, pp. 1139-1145, 2013.

[47] J. Wellington, Educational research: Contemporary issues and practical approaches (2nd ed.), London, England: Bloomsbury Academic, 2015.

[48] D. Yanow, "Qualitative-interpretive methods in policy research," in Hand-book of public policy analysis: theory, politics, and methods, Boca Ra-ton, FL, CRC/Taylor \& Francis, 2007, pp. 405-416. https://doi.org/10.1201/9781420017007.pt8

[49] N. Denzin and Y. Lincoln, "Introduction," in The Sage Handbook of Qualitative Research, Thousand Oaks, SAGE Publications, 2005, pp. 1-32.

\section{Authors}

Juan Habib Bendeck Soto has a Masters in Education, and currently works as an associate EFL professor and Junior Researcher at Uniremington University. He currently publishes articles related to Humanities, Systems Engineering and topics related with ICT in the classroom.

Diana Carolina Toro Ocampo has a Bachelor's degree in Business Administration, currently a candidate for a Masters' degree in Education at Benito Juárez University. She currently works at Uniremington as an EFL professor, and is in charge of all administrative processes related to students' enrollment and educational platform management.

Lued del Carmen Beltrán Colón has a Bachelor's degree in Teaching English and Spanish, currently a candidate for a Masters' degree in Education at Benito Juárez University. She currently works at Uniremington as an EFL professor.

Alejandro Valencia Oropesa has a Bachelor's degree in Secondary Education, with emphasis in English Language. He currently works at Uniremington as an EFL professor, and as an administrative assistant.

Article submitted 2019-11-02. Resubmitted 2019-12-12. Final acceptance 2019-12-12. Final version published as submitted by the authors. 